$$
\text { "tmcs-csapodi" — 2012/3/1 - 0:32 — page } 117 \text { - \#1 }
$$

\title{
Comments on the Remaining Velocity Project with reports of school-experiments
}

\author{
Ödön Vancsó, Attila Komzsík and Csaba Csapodi
}

\begin{abstract}
The aim of this article is to introduce different possible solutions to the exercise referring to the calculation of "remaining velocity" ${ }^{1}$. We explain the possible approaches to the problem with the help of either using the tools of mathematics or other subjects. During the past few years, we have made Hungarian and Slovakian secondary school students solve the exercise, choosing from both children of average and of high abilities. The experince has shown that very few students were able to solve the problem by themselves, but with the help of their teachers, the exercise and the solution has been an eye-opener experience to all of them. A lot of students were even considering to drive more carefully in the future after getting their driving licenses.
\end{abstract}

Key words and phrases: mathematical modeling, interdisciplinarity, realistic problem solving, mathematics and social behavior, graphical solution of a mechanical problem, speeding, Geogebra, DQME project, comparative school experiment in different countries.

ZDM Subject Classification: M10, M50, D50, U30.

\section{Introduction}

In the past half century modelling and application has become part of mathematics education worldwide. This was a long process which started with a conference organized by Hans Freudenthal in 1968 on the topic "How to teach Mathematics so as to be Useful?" as a contrapoint to the "new maths". Results and

This article is based on the framework DQME-II project Comenius Network.

${ }^{1}$ The velocity of a faster car at the point where a slower car can stop.

Copyright (C) 2012 by University of Debrecen 


$$
\text { "tmcs-csapodi" — 2012/3/1 — 0:32 — page } 118 \text { - \#2 }
$$

ideas appeared in a paper [2]. Freudenthal was the founder of a new school in didactics: the so called Realistical Mathematics Education (RME). There is a huge literature about RME, one of the mainstreams in didactics of mathematics. ${ }^{2}$

In the introduction of [1] on the pages 28-29 three different phases of the history of modeling and application were pointed: 1965-1975: advocacy phase, secondly 1975-1990: the developing phase, mainly characterized by curriculum (in UK Mathematics Applicable in US COMAP/UMAP) and finally since the beginning of nineties up today: maturation phase.

During this last phase the empirical studies of teaching and learning of application and modelling have been added to the theoretical bases of the previous phases. The educational policy of the developed countries (OECD) urged the creation of PISA test, one of the most popular and accepted international surveys on the field of mathematics, science and basic language-skills of 15 years old students. The development of mathematical literacy is one of the fields surveyed by PISA tests. This is an important goal of maths teaching today. "Mathematical literacy is an individual's capacity to identify and understand the role that mathematics plays in the world, to make well-founded judgements and to use and engage with mathematics in ways that meet the needs of that individual's life as a constructive, concerned and reflective citizen." 3

The problem examined in this paper is an interdisciplinary topic inspired by a real life event. By working on this problem modeling competency and aspects of mathematical literacy can be tested and developed.

The most frequent reason for deadly public road accidents is fast driving, which is characteristic for the whole of Europe. In Hungary for instance about one third of the deadly accidents are caused by the incorrectly chosen speed. (The exact amount was $28.8 \%$ in 2010, source: National Statistical Office Fast Report.) One of the main features of this phenomenon is that drivers do not have a clear idea about the consequences of fast driving. A great majority of drivers cannot tell what the risk is if they drive $50 \mathrm{~km} / \mathrm{h}$ instead of the permitted $30 \mathrm{~km} / \mathrm{h}$ in the protected urban area, or $140 \mathrm{~km} / \mathrm{h}$ instead of $130 \mathrm{~km} / \mathrm{h}$ on the motorways. Most students obtain their driving license at the end of the secondary school years, or during their university studies, therefore it seems to be relevant to deal with the above mentioned problem during their studies of mathematics and physics. We wanted to solve the problem presented in this paper as a modeling experiment,

\footnotetext{
$2_{\text {www.fi.uu.nl }}$

${ }^{3}$ The whole text in "The PISA 2003 Assesment framework" on pages 24-30 of the following homepage http://www. oecd.org/dataoecd/46/14/33694881.pdf
} 
spending two lessons with it. The results may have a shocking effect on students and consequently they may drive more carefully later on.

\section{Presenting the problem}

The idea of the school-experiment of the following exercise originates from Heinz Böer, the founder of MUED, ${ }^{4}$ and its detailed elaboration is provided by Hans Humenberger, a professor at the University of Vienna.

The problem: In a protected urban area where the permitted speed limit is 30 $\mathrm{km} / \mathrm{h}$, a car is being driven at a speed of $30 \mathrm{~km} / \mathrm{h}$. It is being overtaken by an other car, driven at a speed of $50 \mathrm{~km} / \mathrm{h}$. They are proceeding side by side when two children are running out from the pavement to the street to catch their ball. Both drivers start braking at the same time and both cars have the same brakes. The car with the lower speed can stop just in front of the children. What will be the remaining velocity of the car with the higher speed?

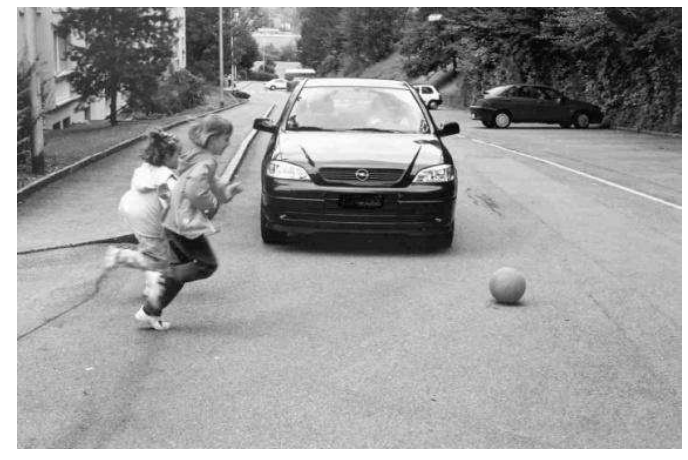

This is an entirely everyday situation and similar cases can occur not only in a protected urban area, but anywhere on the roads.

Our research question was: How can be this problem realized in secondary mathematics teaching in Hungary and Slovakia?

In order to answer this question we presented the problem in Hungary in three different classes within the same secondary school, and in Slovakia in three

\footnotetext{
${ }^{4}$ Mathematik Unterricht Einheiten Datei is the organization of the German teachers of mathematics, its leader is Heinz Böer. Keeping in sight the interrelation of mathematics and the society they elaborated a teaching modul of several ten thousand pages from 1978. This material served as a basis for the DQME EU Project with the participation of 4 countries in 2004-2007 and 11 countries in 2007-2011.
} 


$$
\text { "tmcs-csapodi" — 2012/3/1 - 0:32 — page } 120 \text { - \#4 }
$$

different schools. The detailed description of the schools and classes as well as the different methods of data collection can be found in the Practical experiences part of this article.

\section{Solving the problem}

Humenberger suggests two ways for the solution in his paper [3].

The first is a deductive approach. In this case, the teacher is guiding the students step by step from the expression of the speeds in different units of measurement and determining the braking distance until the final solution of the problem. The author investigates the problem by using 3 test-sheets (A, B and C). In this case, the steps of the solution are as follows:

\section{Test-sheet A}

1. Transforming the speeds into different units of velocity-measurements

2. By means of a concrete example to compose a general formula determining the time required for stopping from velocity $v_{0}$ with deceleration $b\left(t_{B}=\frac{v_{0}}{b}\right)$.

3. Calculating the braking-time in the example above $\left(s_{B}=\frac{1}{2} \cdot v_{0} \cdot t_{B}=\frac{v_{0}^{2}}{2 b}\right)$.

4. Further discussion of the result (e.g. what can be said about the braking distance in case of two or three times higher velocities).

\section{Test-sheet B}

5. By means of a concrete example to plot the distance-velocity function of the braking from velocity $v_{0}$ with deceleration $b$.

6. Determining the function $\left(v=v(s)=\sqrt{v_{0}^{2}-2 b s}\right)$.

7. Further discussion of the result (e.g. in the case of a body braking uniformly with deceleration $b$, what would be its velocity at the half or three quarters of the braking distance).

Test-sheet C

8. Presentation of the concrete example and the estimation of the remaining velocity.

9. Determining the remaining velocity by reading it from the plotted function or rather by substituting the given values to the formula

$$
v_{\mathrm{rem}}=v^{*}\left(s_{B}\right)=v^{*}\left(\frac{v_{0}^{2}}{2 b}\right)=\sqrt{v_{0}^{* 2}-2 b \frac{v_{0}^{2}}{2 b}}=\sqrt{v_{0}^{* 2}-v_{0}^{2}},
$$




$$
\text { "tmcs-csapodi" — 2012/3/1 - 0:32 — page } 121 \text { - \#5 }
$$

where $v_{\text {rem }}$ is the remaining velocity, $v^{*}\left(s_{B}\right)$ is the velocity of the faster car at the end of the braking distance of the slower car, $v_{0}^{*}$ and $v_{0}$ are the initial velocities of the faster and that of the slower car.

10. Completing the solution by taking into account the reaction time.

11. Further investigations.

As an alternative solution, the author suggests the so called "throwing to the deep water", that is, after having presented the example, the solution is entrusted to the students who may work in groups just as well.

\section{Further solutions}

In the following, we show three solutions differing from the above mentioned methods.

\subsection{Geometrical approach ${ }^{5}$}

This method is suggesting a geometrical approach by starting out from the chart of the time-velocity function, instead of the distance-velocity function and solving the problem by determining the areas under the curves. Let's have a look at the time-velocity diagram of the two cars:

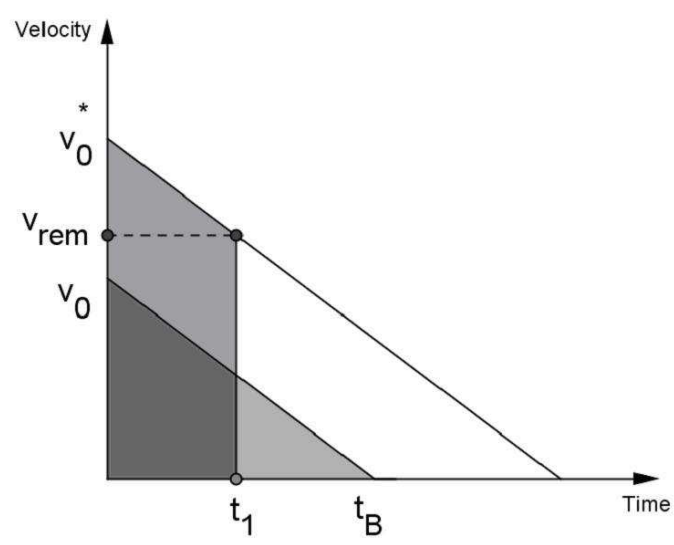

${ }^{5}$ Originates from Ödön Vancsó [4].
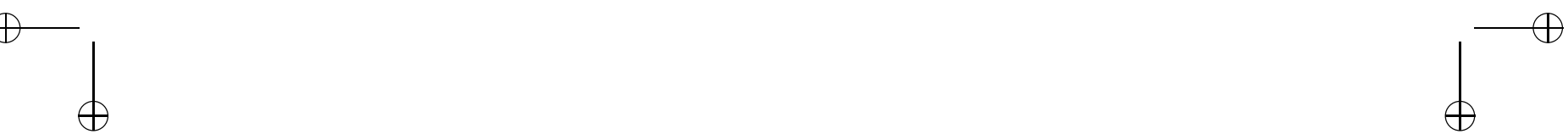
The distance covered by the slower car is equal to the area of the light grey right-angled triangle therefore the distance covered by the faster car should be the same. The question is how much its speed will decrease by the end of the braking distance. The distance covered by the faster car until the $t 1$ point of time is equal to the area of a trapezium (represented in darker grey background on the figure). Based on this: $\frac{v_{0}^{2}}{2 b}=\frac{v_{0}^{*}+v_{\mathrm{rem}}}{2} \cdot t_{1}$. Since $v_{\mathrm{rem}}=v_{0}^{*}-b \cdot t_{1}$ consequently $t_{1}=\frac{v_{0}^{*}-v_{\mathrm{rem}}}{b}$. Substituting these values into the equation describing the equality of the territories and multiplying both sides by $2 b$ then arranging the terms, we get $v_{0}^{2}=v_{0}^{* 2}-v_{\text {rem }}^{2}$ and so $v_{\text {rem }}^{2}=v_{0}^{* 2}-v_{0}^{2}$. It is important to observe that the remaining velocity will not depend on the deceleration of the cars.

On the basis of the following figure, the problem can be solved also by taking into account the reaction time of the drivers. In this case, the formula can be obtained by equalizing the areas of a trapezium and a pentagon. In this case, the calculations become more complicated.

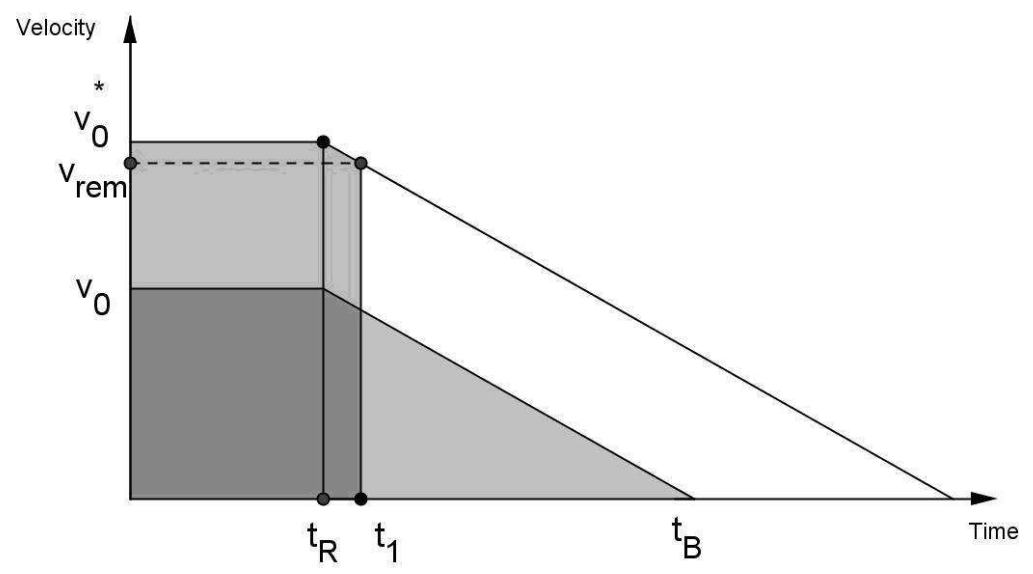

In the following, we designate with $s_{R}$ and $s_{B}$ the distances covered by the slower car during the reaction-time and during the braking-time to full stop, and with $s_{R}^{*}$ and $s_{B}^{*}$ the distances covered by the faster car during the reaction-time and during the braking-time from starting the braking until the slower car stops at the braking distance. The distance covered by the slower car until full stop is: $s_{R}+s_{B}=\frac{t_{R}+t_{B}}{2} \cdot v_{0}$. The distance covered by the faster car during $t_{1}$ can be described as $s_{R}^{*}+s_{B}^{*}=t_{R} \cdot v_{0}^{*}+\frac{v_{0}^{*}+v_{\text {rem }}}{2} \cdot\left(t_{1}-t_{R}\right)$. Supposing that the faster car will start braking at least by the time when the slower car stops (that is if $s_{R}+s_{B}>s_{R}^{*}$ ), its velocity at the braking distance of the slower car is: 


$$
\text { "tmcs-csapodi" — 2012/3/1 - 0:32 — page } 123 \text { - \#7 }
$$

$v_{\text {rem }}=v_{0}^{*}-b \cdot\left(t_{1}-t_{R}\right)$. Out of this $t_{1}=\frac{v_{0}^{*}-v_{\text {rem }}}{b}+t_{R}$. Substituting this into the equation describing the equality of the territories and multiplying both sides by $2 b$ wen get $b \cdot\left(t_{R}+t_{B}\right) \cdot v_{0}=2 b \cdot t_{R} v_{0}^{*}+v_{0}^{* 2}-v_{\text {rem }}^{2}$.

Arranging this equation and using that in the case of the slower car $\frac{v_{0}}{b}=$ $t_{B}-t_{R}$ we get that $v_{\text {rem }}=\sqrt{v_{0}^{* 2}-v_{0}^{2}+2 b t_{R}\left(v_{0}^{*}-v_{0}\right)}$ if $s_{R}+s_{B}>s_{R}^{*}$. Naturally if the faster car does not even start braking where the slower car stops i.e. if $s_{R}+s_{B} \leq s_{R}^{*}$ then $v_{\text {rem }}=v_{0}^{*}$.

Evaluating the formula, we have to emphasize that if we also take into consideration the reaction-time when calculating the remaining velocity, the result will depend not only on the value of the reaction-time, but also on the value of the deceleration $b$.

Solving the problem this way it is required that the students understand why the area under the time-velocity function represents the distance covered by a body in motion (it is approximatively explained in the original version of the solution). Besides, after having found a good demonstration, it transforms the problem into a geometrical problem showing the students the complexity of mathematics. It seems to be feasible that the students themselves will try to solve the problem following this direction.

\subsection{The physical approach ${ }^{6}$}

A completely different approach for solving the problem is the physical approach. The calculation is based on the employment of the kinetic and the braking energies. It is well-known that a moving body with decreasing speed $E_{\text {kin }}=E_{\text {kin }_{0}}-E_{\text {break }}$ where $E_{\text {kin }_{0}}$ is the initial kinetic energy of the moving body. Considering that the two cars are braking with the same power and they are covering the same distance, their braking energy should be equal. Furthermore we know that the slower car will stop, therefore its initial kinetic energy should be equal to the braking energy of both cars. Let's designate the initial kinetic energy of the slower car, the initial kinetic energy of the faster car and the momentary kinetic energy of the faster car respectively with $E_{\mathrm{kin} a_{0}}, E_{\mathrm{kin} b_{0}}, E_{\mathrm{kin} b}$. In accordance with the preceding $E_{\operatorname{kin} b}=E_{\operatorname{kin} b_{0}}-E_{\text {break }}$ and $E_{\operatorname{kin} b}=E_{\operatorname{kin} b_{0}}-E_{\operatorname{kin} a_{0}}$ because $E_{\text {kin } a_{0}}=E_{\text {break }}$. Using the formula for the kinetic energy (and assuming that both cars have the same $m$ mass): $\frac{1}{2} m v_{b}^{2}=\frac{1}{2} m v_{b_{0}}^{2}-\frac{1}{2} m v_{a_{0}}^{2}$ out of which

${ }^{6}$ Its description follows the method given by Tamás Gruber (a math's-phys trainee teacher of Csaba Csapodi), and uses the remarks of Laszló Kvasz.

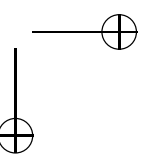


$v_{b}^{2}=v_{b_{0}}^{2}-v_{a_{0}}^{2}$, that is $v_{b}=\sqrt{v_{b_{0}}^{2}-v_{a_{0}}^{2}}$ which is the same formula that we have got for the remaining velocity in the former case.

This solution has the advantage of emphasizing the interrelation between the subjects of mathematics and physics. Its disadvantage, however, is that it takes for granted such knowledge and formulas, the real content of which are not as plausible as in the original case. Using the formula given for the calculation of the kinetic energy is not so much different from the case when we describe the distance-velocity function of a body moving with uniformly decreasing speed. Therefore, we suggest this method rather as a curiosity than for a solution.

\subsection{Computer technique approach}

Perhaps this cannot be called a solution, still, we have to mention a third possibility here for calculating and demonstrating the relevant data. Using a computer, we can display the relevant functions and the relevant velocity by means of the Geogebra program.

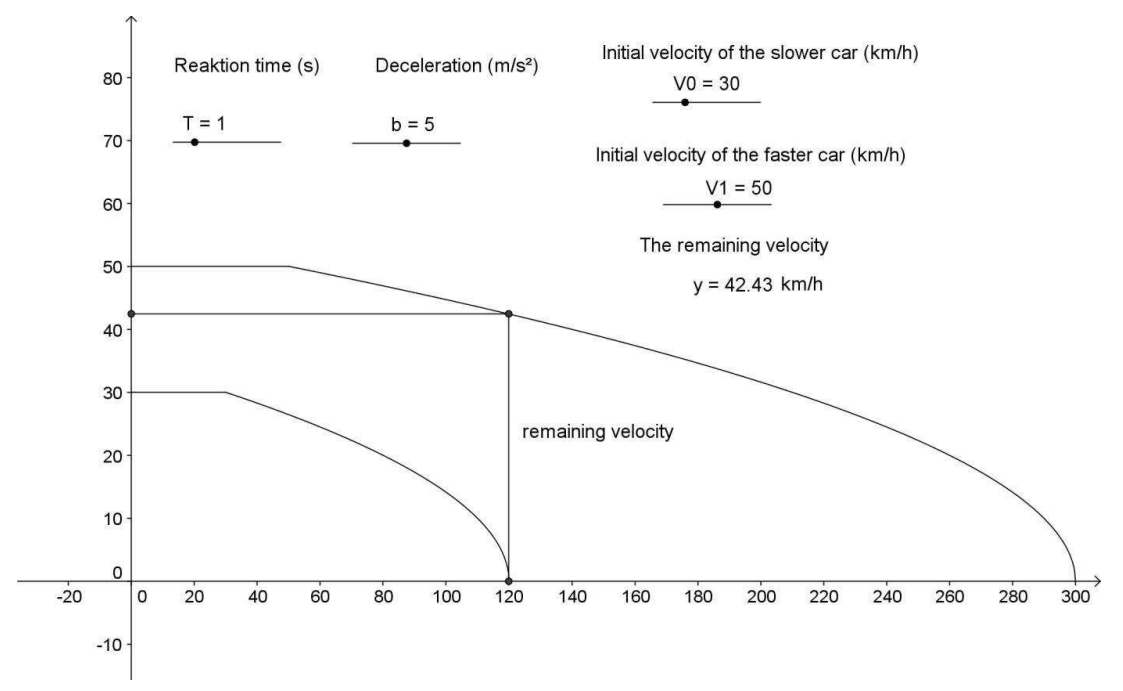

We can observe the changes of the velocities of the two cars in the function of the covered distance, without and with the reaction-time. The input data (initial velocities, deceleration, and reaction time) can be chosen arbitrarily. The program calculates the remaining velocity for each case. It is important to mention that in this case the mathematical methods are embedded into the programs, therefore in this case some rudimentary mathematical knowledge is essential to understand 
"tmcs-csapodi" — 2012/3/1 - 0:32 — page 125 — \#9

this approach completely. Referring back to the solution given by Humenberger, it may be also necessary in this case to work out the formula of the distancevelocity function, but the plotting of the functions and the reading of the results can be attained much faster and more accurately than by means of hand-plotted diagrams. Therefore, this approach can be considered mainly as a supplement to the other methods.

\section{Practical experiences}

In the past two years we have tried different versions of the solution of the problem in several schools in Hungary and in Slovakia (see [4]). We had the possibility to make experiments with students at the Trefort Ágoston Grammar School in Budapest, whereby we tested two versions of the solutions, and drew a lesson from the results to work out a third method, accomplished also by the students. This experiment (which has not been mentioned in [4]) had been accomplished by Csaba Csapodi.

It is important to mention, that in both countries we can detect the difficulties harmonizing the physical and mathematical curriculum, but this phenomenon affects mainly the lower classes education. All the investigated students both in Hungary and Slovakia have learnt the necessary related theory in physics and in mathematics (e.g. solving quadratic equations, handling different types of graphs, modeling real life problems).

\subsection{Class 11 faculty and the deductive way (Hungary)}

First, we examined the deductive way of solving the problem in class 11, where the group of students showed special interest in mathematics and were motivated. The students followed the general course of the solution and we reached the desired solution step by step. The students received the three test-sheets and they answered the questions one by one. Naturally, they got assistance from the teacher whenever it was needed. Primarily it was required at the 6 th question of the B-sheet.

Characteristically, at the beginning of the C-sheet the students estimated the remaining velocity at around $35 \mathrm{~km} / \mathrm{h}$ in the case when the cars ran at speeds of 30 and $50 \mathrm{~km} / \mathrm{h}$. This is remarkable because this value is higher than the one obtained from the other two classes, where the estimation was not preceded by any calculation. On the other hand, in class 11 they previously had such results 


$$
\text { "tmcs-csapodi" — 2012/3/1 - 0:32 — page } 126 \text { — \#10 }
$$

(e.g. the decreasing concave shape of the distance-velocity function) forecasting that the remaining velocity will be high. From the discussions after having solved the problem it turned out that the result had a great effect on the students. The following remark bursted out from one of the boys: "I would not have thought of it, and I will never exceed the prescribed speed limit."

In spite of the positive results mentioned above, we are not considering this method as a good one, since the students cannot realize for a long time what the purpose of the investigations is. We had to keep up their interest with different remarks until we reached the C-sheet when the students became interested. From a didactical point of view, we consider it more appropriate if the students know clearly from the beginning (especially in the case of such an interesting complex task) what the reason for the preliminary calculations is. Another reason why we are not considering the deductive method as appropriate because in this case we reach the result not by starting from the problem but rather we build up the problem from the knowledge of the solution. We have tried to eliminate this problem during the experiments with the fourth students-group.

\subsection{Class 10 study-group and the "deep water" (Hungary)}

We wanted to look for the possibility to also test the second method suggested by Humenberger using a student-group. We devoted 2 hours of a class 10 studygroup to this experiment. Consequently, the members of this age-group were selected again from the best students of mathematics of the reputed school. At this occasion they could work in groups of $2-3$, but apart from the presentation of the problem, they didn't get any assistance to the solution of the problem (at least at the beginning).

Their estimation for the remaining velocity scattered around $20 \mathrm{~km} / \mathrm{h}$ in the case when the cars ran at speeds of 30 and $50 \mathrm{~km} / \mathrm{h}$., thus the answers were much lower than the real value or that of the "well-founded" answers of the class 11 students.

During the available time-limit, only one of the 6 study-groups could make a real progress in solving the problem (with some assistance from the teacher they could determine the right value of $40 \mathrm{~km} / \mathrm{h}$ as for the remaining velocity), but the other students could not make any considerable progress.

Relying upon these findings (and upon other educational experiences of ours), we can conclude that this method is too difficult for students and we cannot expect them to solve the problem being left entirely alone. It seems meaningful to make 


$$
\text { "tmcs-csapodi" — 2012/3/1 - 0:32 — page } 127 \text { — \#11 }
$$

university students solve this problem as well, which may provide interesting results.

\subsection{Experiences in Slovakia}

Under the guidance of Attila Komzsik, we dealt with the problem at three schools in Slovakia, where the teaching language was Hungarian.

A) The students of the János Selye Grammar School in Komárno - one of the best secondary schools in the county - tried to solve the problem by working in groups, but practically without help and they succeeded. They were highly motivated, especially well-educated and by no means average students.

Their solutions are systematic, well-perspicuous and serried. At the same time it is interesting that while estimating the remaining velocity these students expect it as the difference of the speed of the faster and the slower car.

In the following, we show a part of a typical solution from this group. The other solutions were similar. We can see that not only the necessary algebraic transformations were carried out correctly by the students, but also they worked very precisely in plotting the results and making their remarks.

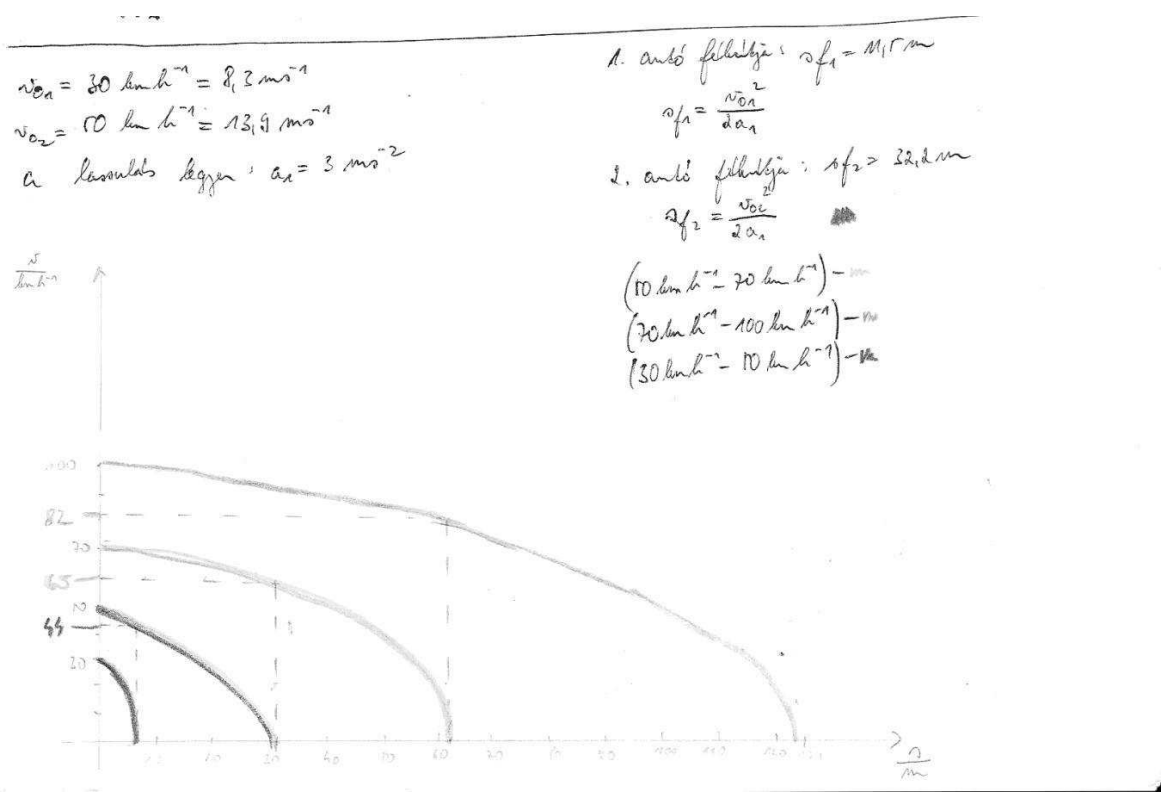


B) At the secondary school in Tornalja the students tried to work at home independently. This is a secondary school of an average level in Slovakia, where the subjects of mathematics and physics are taught in normal weekly hours. The students tried to solve the problem on the bases of the instructions they had been given at school.

Hereby we show the part of a student's work. One can see that the student substitutes in formulas, so we suppose that rather the teacher's instructions helped him calculating the results and he did not rely on his own thoughts.

$$
\begin{aligned}
& \begin{array}{l}
\text { (4) } A: 30 \mathrm{~km} / \mathrm{h}=8,3 \mathrm{~m} / \mathrm{s} \quad \text { Kaiain Rotbet } \\
B: 50 \mathrm{~km} / \mathrm{h}=13,8 \mathrm{~m} / \mathrm{s} \\
a=5 \mathrm{~m} \cdot \mathrm{s}^{2}
\end{array} \\
& \text { Or A autó féltávolsága. } \\
& s=\frac{v_{0}^{2}}{2 a}=\frac{8,3^{2}}{2.5}=\frac{68,89}{10}=6,89 \mathrm{~m} \\
& \text { A } B \text { auto pillanyatmi sebessége: } \\
& v_{s}=\sqrt{v_{0}^{2}-2 a s} \\
& V(6,89)=\sqrt{13,8^{2} \cdot 2 \cdot 5 \cdot 6,89} \\
& v=11,02 \mathrm{~m} / \mathrm{s}=3,9,67 \mathrm{~km} / \mathrm{h}
\end{aligned}
$$

C) The students of the Galileo School in Bratislava with bilingual teaching, worked in small groups. Their test-sheets reflect that in fact they tried to solve the problem independently: this is why we show several solutions from them:

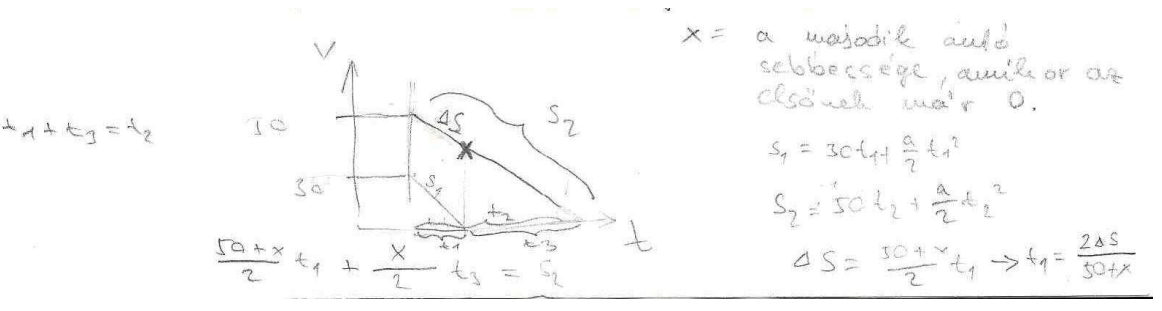


This solution has several points of interest. Firstly, their estimated value for the remaining velocity $(9-12 \mathrm{~km} / \mathrm{h})$ on the top of the test-sheet is extremely low. Later on they tried to apply the formula for the uniformly decelerating motion with relatively little success. At the same time, at the bottom of the test-sheet (as seen above) they were trying to use a graphical approach in a remarkable manner, but they failed since they tried to express the difference of the covered distance by the two cars and to create an (incorrect) equation out of it. In the end they realized their failure.

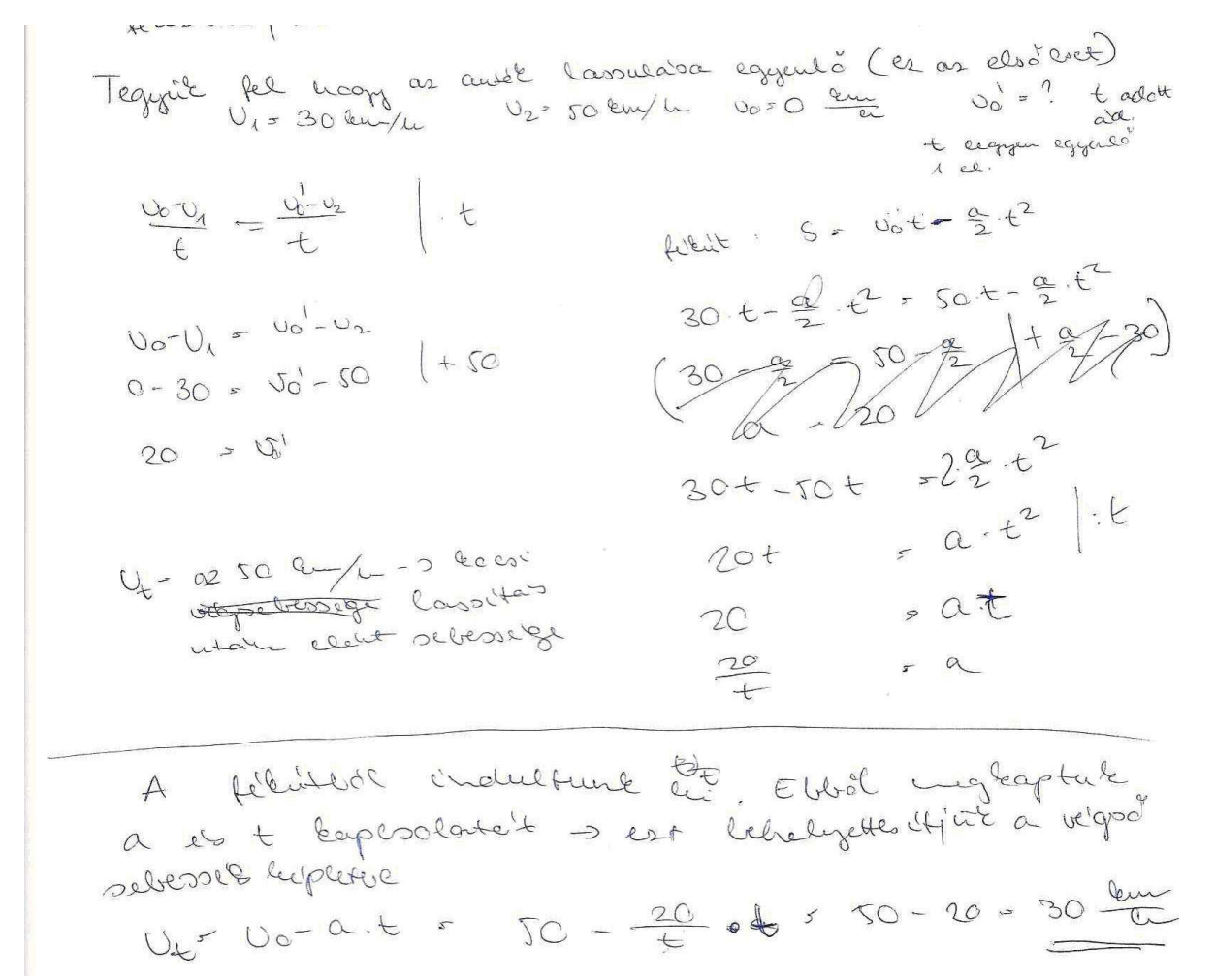

Another student-group started from equalizing the braking distances of the two cars, then they assumed (incorrectly) that the braking-times were also equal. They continued with the obtained wrong data, therefore they could not solve the problem properly. Another mistake in their solution was that they were not dealing with the necessary transformation of the different physical quantities to some common units of measurements. 


$$
\text { "tmcs-csapodi" — 2012/3/1 — 0:32 — page } 130 \text { — \#14 }
$$

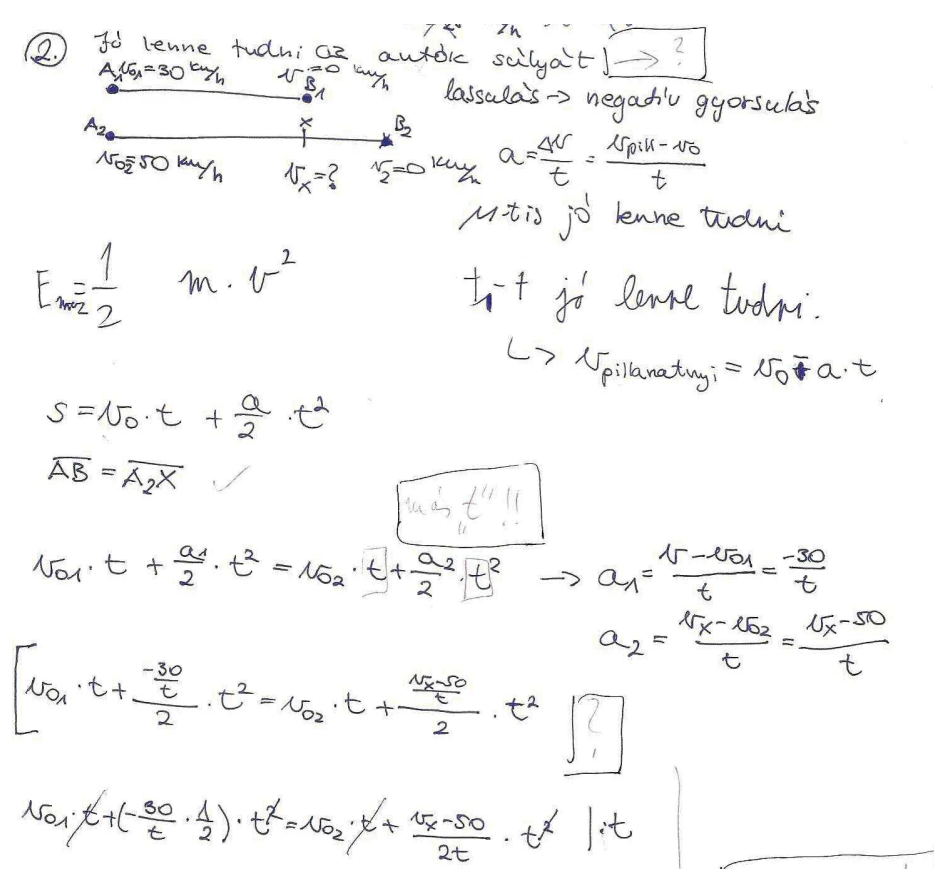

After having revised their original train of thoughts, this group realized for some unknown reasons that the remaining velocity should be greater than the speed difference of the two cars. The odd part of their solution was that it occurred to them - at least at the level of mentioning - that they should employ the kinetic energies for solving the problem. At the same time they required some more data (frictional coefficients, masses of the cars) that were not necessary for the solution. Similarly to the previous student-group, they also started from the (incorrect) assumption that the braking-time of the two cars were equal, consequently their lengthy deduction have not produced the correct solution.

These results show again that only the students of exceptional abilities were able to solve the problem independently (or in groups). The average or below the average students were able to solve the problem only under the guidance of the teacher.

\subsection{On a new way with Class 12 (Hungary)}

Having accomplished the above mentioned school-experiments in 2009/2010, we had again the possibility to demonstrate the problem in a graduating class, 
"tmcs-csapodi" — 2012/3/1 - 0:32 - page 131 - \#15

Comments on the Remaining Velocity Project with reports of school-experiments

where the subject of mathematics is taught in the basic 3 lessons a week. Contrary to the previous 2 groups, they were not especially outstanding in mathematics and they were not really interested in the subject either, their only motivation was to get a good mark at the end of the year. Their knowledge of mathematics could be considered as the national average in Hungary. We have elaborated a third method for the steps of solving the problem, namely we started from the presentation of the problem and with the estimation of the remaining velocities and by thinking together with the students and continuously supporting them, we proceeded towards the solution, however, we always encouraged them to work out the solutions by themselves. This way the teacher was only a moderator between the students and the problem.

We extended this concept with two other ideas. The first was the distribution of a questionnaire among the students before starting to solve the problem. After having presented the problem we asked them to make estimation for the remaining speed in three cases. The result is shown in the following table:

\begin{tabular}{|c|c|c|}
\hline $\begin{array}{c}\text { speed of the two cars } \\
\text { in } \mathrm{km} / \mathrm{h}\end{array}$ & $\begin{array}{c}\text { the mean value of the } \\
\text { answers in } \mathrm{km} / \mathrm{h}\end{array}$ & $\begin{array}{c}\text { the dispersion of the } \\
\text { answers in } \mathrm{km} / \mathrm{h}\end{array}$ \\
\hline 30 and 50 & 19,5 & 5,5 \\
\hline 50 and 70 & 25 & 11 \\
\hline 70 and 100 & 38 & 20 \\
\hline
\end{tabular}

It is clearly seen that the students underestimated the real values to a great extent. (The real values for remaining velocity of the faster car should have been 40, 50 and $70 \mathrm{~km} / \mathrm{h}$ respectively without taking into account the reaction-time.) Interestingly enough the increasing relative dispersions of the answers show that some of the students made a better estimation at higher speeds.

The great majority of the students have found the real values so ridiculous that they became interested in finding the reasons. We emphasize that the majority of these students have never shown any special interest in mathematics.

We would not like to enter into the details of the exercise here, but we are planning to present it in a different article by Csaba Csapodi with a full account of the questionnaire and the statistical analysis of the answers.

What has become clear from the survey is that these students basically understood the non-trivial and not simple calculations (the test-sheets were anonym). Another interesting result was that as a result of the exercise, about two-thirds of these students decided to drive more carefully in the future. Let it be true at least in one case - it has been worth to have spent the time on the subject. 
The last question leads us to the second phase of the experiment. At the beginning of the exercise we asked the students to keep a close look at the results because they were expected to present the problem at home in front of their parents and to ask them to fill in a similar questionnaire. This has been achieved with 16 parents ( 4 students did not make it at home, on the other hand 4 students had it made by both parents). The table below shows the results:

\begin{tabular}{|c|c|c|}
\hline $\begin{array}{c}\text { speed of the two cars } \\
\text { in } \mathrm{km} / \mathrm{h}\end{array}$ & $\begin{array}{c}\text { the mean value of the } \\
\text { answers in } \mathrm{km} / \mathrm{h}\end{array}$ & $\begin{array}{c}\text { the dispersion of the } \\
\text { answers in } \mathrm{km} / \mathrm{h}\end{array}$ \\
\hline 30 and 50 & 28 & 8 \\
\hline 50 and 70 & 45 & 14 \\
\hline 70 and 100 & 62,5 & 21 \\
\hline
\end{tabular}

As a matter of fact it is difficult to draw strong and exact conclusions from the results, since we do not know how the exercise was carried out by the students, but we can state one thing: the parents (all of them practicing drivers) were able to give a better estimation of the remaining velocities than the students. Later the students had to present the general steps of the solution to the parents, then they asked them to fill in a short questionnaire. The obtained results will also be presented in the above mentioned article, but the main results were as follows:

1. The major part of the parents understood the presentation of their children $(87 \%)$

2. The major part of the parents declared that in the light of the results they will drive more carefully $(76 \%)$

3. The majority of the parents would find it useful if their children - among the subject matters of mathematics - also dealt with problems connected to everyday life. This is a rejoicing piece of information.

\section{Conclusions}

As a summary we can conclude that the remaining velocity problem can be adapted both in Hungary and Slovakia to secondary mathematics teaching. If we compare the observations made in the two countries we can say that in both countries very few students are able to solve the problem on their own, nevertheless they were aware of the required mathematical and physical instruments. At the same time the majority of them was interested in answering the question and was wondering when came to know the answer. 
We are convinced that such problems (based on everyday life, using the secondary school curriculum of mathematics and/or physics) should be part of the secondary school education both in Hungary and Slovakia.

\section{References}

[1] W. Blum, P. L. Galbraith and H.-W. Henn (eds.), Modelling and Applications in Mathematics Education, Springer, New York, 2007.

[2] H. Freudenthal, Why to Teach Mathematics so as to Be Useful?, Educational Studies 1, 1968, 3-8.

[3] H. Humenberger, Brake application and remaining velocity, in: First annual publication of the Comenius Network DQME II. Dortmund, (Henn, H.-W. \& Meier, S., eds.), Technische Universität Dortmund, 2008.

[4] A. Komzsik and Ö. Vancsó, Modeling and motivation, in: Second annual publication of the Comenius Network DQME II. Dortmund, (Henn, H.-W. \& Meier, S., eds.), Technische Universität Dortmund, 2009.

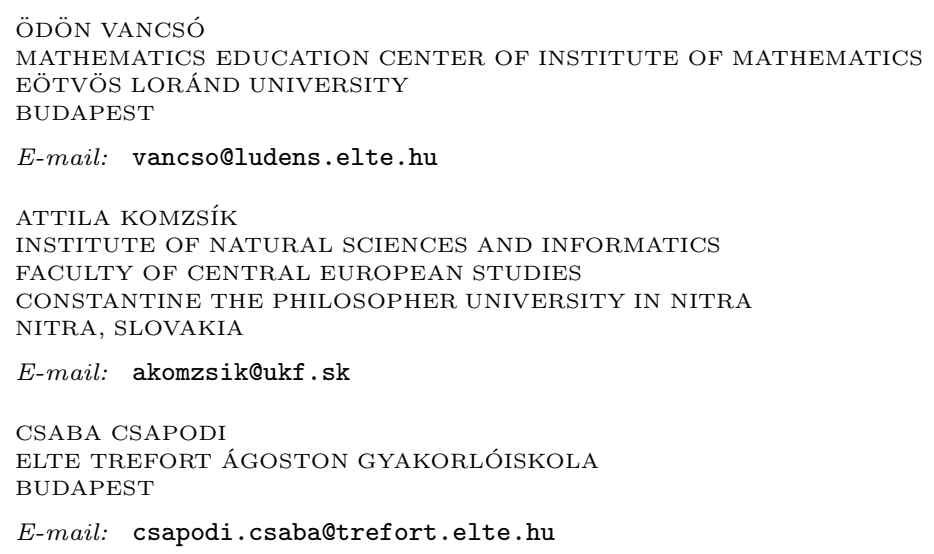

(Received May, 2011) 